LA W REN CE LIVERM ORE N A TIO NAL LABORATORY

LFR Demonstrator Materials

Viability

M. Caro

August 4, 2006 
This document was prepared as an account of work sponsored by an agency of the United States Government. Neither the United States Government nor the University of California nor any of their employees, makes any warranty, express or implied, or assumes any legal liability or responsibility for the accuracy, completeness, or usefulness of any information, apparatus, product, or process disclosed, or represents that its use would not infringe privately owned rights. Reference herein to any specific commercial product, process, or service by trade name, trademark, manufacturer, or otherwise, does not necessarily constitute or imply its endorsement, recommendation, or favoring by the United States Government or the University of California. The views and opinions of authors expressed herein do not necessarily state or reflect those of the United States Government or the University of California, and shall not be used for advertising or product endorsement purposes.

This work was performed under the auspices of the U.S. Department of Energy by University of California, Lawrence Livermore National Laboratory under Contract W-7405-Eng-48. 


\section{Contents}

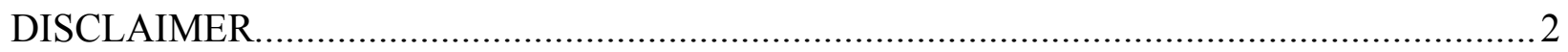

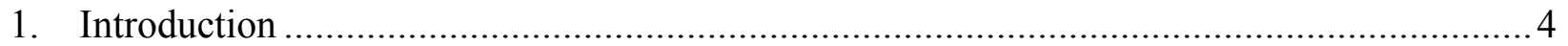

2. Approach to Materials Development .................................................................. 4

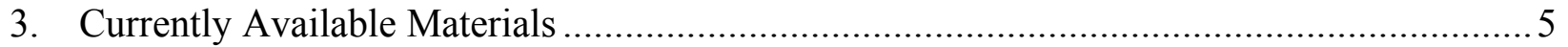

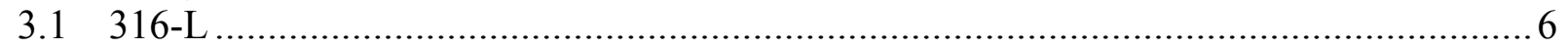

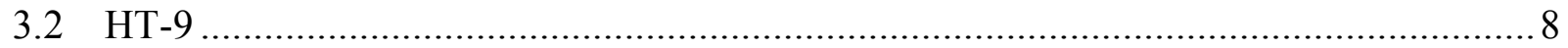

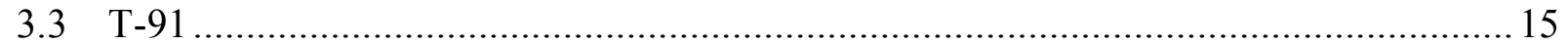

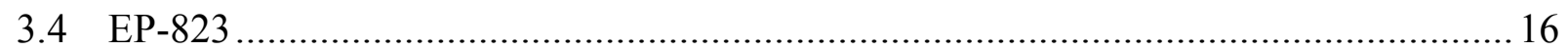

4. Development of Advanced Materials ..................................................................... 17



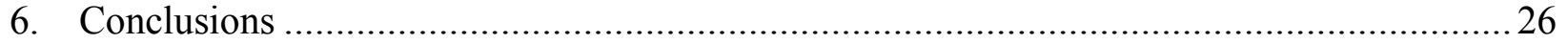






\title{
LFR Demonstrator Materials Viability
}

\author{
M. Caro \\ July 27, 2006
}

\section{Introduction}

Interest in fast reactor development has increased with the Department of Energy's introduction of the Global Nuclear Energy Partnership (GNEP) [1]. The GNEP program plans development of a sodium cooled Advanced Burner Reactor (ABR) that can be used to reduce the amount spent LWR fuel in storage and the number of high level waste sites needed for expansion of nuclear power throughout the world over the $21^{\text {st }}$ century. In addition, the program proposes to make nuclear power more available while reducing the proliferation concerns by revising policies and technology for control of weapons useable materials. This would be accomplished with establishment of new institutional arrangements based on selective siting of reprocessing, enrichment and waste disposal facilities. The program would also implement development of small reactors suitable for use in developing countries or remote regions with small power grids.

Over the past several years, under the Department of Energy (DOE) NERI and GEN IV programs research has been conducted on small lead cooled reactors. The Small Secure Transportable Autonomous Reactor (SSTAR) [2] is the most recent version of this type of reactor and research is continuing on it in the GEN IV program in parallel with GNEP. SSTAR is a small (10MWe-100MWe) reactor that is fueled once for life. It complements the GNEP program very well in that it serves one of the world markets not currently addressed by large reactors and its development requirements are similar to those for the ABRs. In particular, the fuel and structural materials for these fast spectrum reactors share common thermal and neutron environments. The coolants, sodium in ABR and lead or lead-bismuth eutectic (LBE) in SSTAR, are the major developmental difference.

This report discusses the status of structural materials for fast reactor core and primary system components and selected aspects of their development.

\section{Approach to Materials Development}

The timeline for the material development will be different depending on the test facilities available and selection of the demonstration reactor design conditions. There are two distinct options available: 1) build a technology demonstrator plant based on currently available materials, and 2) delay the demonstration reactor testing until materials suitable for the commercial design are available. The development path for materials for these two 
alternatives is clearly different and the impact the choice has on the design of a commercially viable design is difficult to assess. Reference [2] discusses the possibility of constructing an early technology demonstrator based on the use of the currently available materials. This approach constrains the operating parameters of the demonstration reactor to less than those currently identified as desired for the commercial plant and may also require some qualification testing of the existing materials. And all though such a facility may support the common effects testing of advanced materials the commercial design that can ultimately be supported may be less attractive than the alternative of delaying the construction of the commercial demonstrator until a demonstration plant more prototypical of the commercial design can be constructed using advanced materials. On the other hand, there are few sodium cooled fast reactors available for possible testing and they are all older foreign plants with limited remaining available testing life. Materials testing in LWRs or accelerator facilities will significantly extend the development time and the need for combined effects testing will be difficult to achieve. The selection of one or the other of these approaches is impacted by the ultimate scope of the GNEP program since it is focused on development of an ABR and the associated fuel cycle. (Current GNEP plans take option 1 with construction of a sodium cooled Advanced Burner Test Reactor (ABTR). Because of these uncertainties the following discussion of the materials development has been separated into two major sections. In Section 3, the properties of the most suitable currently available materials are discussed and further effort that may be required for their qualification is identified. In Section 4, advanced material candidates are identified and analysis methods that can lead to development of the materials most suitable for the currently preferred commercial designs are discussed.

\section{Currently Available Materials}

Development of structural and fuel cladding materials for SSTAR is challenged by the need to demonstrate the adequacy of the materials for the combined neutron, temperature and chemical environment over the long core lifetime required without refueling. The most attractive concepts for SSTAR require core outlet temperature above $550{ }^{\circ} \mathrm{C}$ and the more advanced lead cooled reactors, envisioned for hydrogen production, propose core outlet temperature of $800{ }^{\circ} \mathrm{C}[3]$. In addition, the long-life core design will experience radiation exposures in peak locations at or above 150dpa depending of reactor life. Structural and cladding materials for these conditions are not currently available and neither is there an experimental facility that can subject materials to this combined environment. It will require an approach that combines material modeling, data gathered from separate effects experiments, including irradiation of materials in sodium and water cooled test reactors. It will also be necessary to construct a demonstration reactor prior to deployment of a commercial design.

There are four materials, depending on the operational temperature and lifetime requirements that are suitable for use in lead or LBE test facilities: 316-L, HT-9, T-91 and the Russian alloy EP823, see nominal chemical composition in Table 1 as compared to commonly used austenitic steel 316-L. 
Table 1: Chemical composition of ferritic-martensitic HT-9, T-91, and EP-823 steels compared to austenitic steel 316-L.

\begin{tabular}{|l|l|l|l|l|l|l|l|l|l|l|l|l|l|}
\hline Material & $\mathbf{C}$ & $\mathbf{S i}$ & $\mathbf{M n}$ & $\mathbf{S}$ & $\mathbf{P}$ & $\mathbf{W}$ & $\mathbf{C r}$ & $\mathbf{N i}$ & $\mathbf{M o}$ & $\mathbf{V}$ & $\mathbf{N b}$ & $\mathbf{N}$ & $\mathbf{T i}$ \\
\hline EP823 & 0.18 & 1.05 & 0.6 & --- & 0.012 & 0.65 & 11.4 & 0.7 & 0.67 & 0.4 & 0.2 & --- & 0.03 \\
\hline 316-L & 0.035 & 0.08 & 2.0 & 0.03 & 0.040 & --- & 16 & 10 & 2 & --- & --- & --- & --- \\
\hline HT-9 & 0.2 & 0.25 & 0.5 & ---- & ---- & 0.5 & 12 & 0.56 & 1 & 0.3 & --- & --- & --- \\
\hline T-91 & 0.1 & 0.4 & 0.45 & ---- & ---- & ---- & 9 & --- & 1 & 0.2 & 0.08 & 0.05 & --- \\
\hline
\end{tabular}

Note that, only a limited number of materials are presently incorporated into the relevant ASME section for nuclear operation at high temperature $(316,304$, Alloy $800 \mathrm{H}, 2.5 \mathrm{Cr}-1 \mathrm{Mo}$ with $9 \mathrm{Cr}-1 \mathrm{MoV}$ in preparation) [4]. Type-304 stainless steel is one of the major construction materials used at present for nuclear reactor internals and its associated components. Alloy $800 \mathrm{H}$ is a nickel-iron-chromium alloy with higher creep-rupture strength than alloy 800 . The higher strength results from close control of the $\mathrm{C}, \mathrm{Al}$, and Ti contents in conjunction with a high-temperature anneal. It is used in chemical and petrochemical processing, in power plants for super-heater and reheater tubing, in industrial furnaces, and for heat treating equipment. Cr-Mo steels are used in high temperature applications in the petrochemical industry and in electric generating power stations. Resistance to creep is promoted by the addition of $\mathrm{Mo}$ and $\mathrm{Cr}$ and resistance to corrosion by $\mathrm{Cr}$.

In order to meet licensing requirements, development of appropriate code cases will be needed for materials that are currently being investigated and show superior physical or mechanical properties.

\section{$3.1316-L$}

There is a large database on mechanical properties of austenitic steels at high dose rates $\left(10^{6}\right.$ $\mathrm{dpa} / \mathrm{s}$ ) and temperatures from 370 to $550{ }^{\circ} \mathrm{C}$ obtained from previous fast reactor programs in US. Austenitic stainless steels 316 SS with about $20 \%$ cold work are the preferred cladding and wrapper material of commercial FBRs existing in the world. These stainless steels are important candidates for components operating in temperature ranges of $100-300{ }^{\circ} \mathrm{C}$, like the first wall of the International Thermonuclear Experimental Reactor (ITER) and are currently being considered in the Supercritical-Water-Cooled Reactor (SCWR) fuel assemblies and core internals [4]. Because of its high swelling rate it is not favored for use in regions of high neutron dose. Austenitic stainless steels operating at temperatures in the range $280-350{ }^{\circ} \mathrm{C}$ and doses beyond $5 \mathrm{dpa}$ are affected by strong radiation hardening coupled with reductions in uniform strain, and fracture toughness. Irradiation-assisted stress corrosion cracking is of significant concern at temperatures below $350{ }^{\circ} \mathrm{C}$. Above $350{ }^{\circ} \mathrm{C}$, stainless steels microalloyed with $\mathrm{Ti}, \mathrm{B}$, and $\mathrm{P}$ for swelling resistance and higher creep strengths are required; examples include the Japanese PNC 316, the French 15-15 Ti alloy, and the US HT-UPS alloy. 
PNC 316 is a modified 316 stainless steel for high burnup fast reactor core applications. The steel exhibits excellent characteristics in creep rupture strength and swelling resistance, and is superior to any other Type 316 class stainless steels, i.e. $10^{4} \mathrm{~h}$ creep rupture strength greater than $200 \mathrm{MPa}$ at $650{ }^{\circ} \mathrm{C}$ and swelling less than $1 \%$ at neutron fluence of $1.910^{23}$ $\mathrm{n} / \mathrm{cm}^{2}(\mathrm{E}>0.1 \mathrm{MeV})$. The reliability of this steel (dimensional stability, compatibility with sodium and high burnup design target) has been confirmed by fast reactor irradiation of 26000 fuel elements and 500 fuel sub-assemblies [5].

Titanium-modified austenitic stainless steels, like 15-15 Ti alloy, show improved mechanical response and/or swelling resistance in irradiations carried out in Phenix and Rapsodie fast reactors [6]. Ti- or Nb-stabilized steels, like D91, and PCA, have been the subject of numerous published radiation effect studies; D91 is an alloy developed for U.S. Breeder Reactor Program, and PCA is U.S. Fusion Material Program's Prime Candidate Alloy [7].

Alloy 316-L is an austenitic steel that has been used extensively in past sodium cooled fast reactors and a Ti-modified version of $316 \mathrm{SS}$, alloy D9, is currently planned for use for selected parts of India's new 500MWe demonstration fast reactor [8]. Residence time of the fuel assembly is limited by the void swelling of the wrapper material. This alloy shows an incubation dose for swelling that goes beyond $100 \mathrm{dpa}$ and therefore could be suitable for the wrapper and clad tubes for the Indian 500 MWe Prototype Fast Breeder Reactor (PFBR).

As said before, previous U.S. fast reactor development programs concentrated in properties of austenitic stainless steels at high dose rates $\left(10^{6} \mathrm{dpa} / \mathrm{s}\right)$ and temperatures from 370 to 550 ${ }^{\circ} \mathrm{C}$. Today, ongoing research focus on dose-rate effects on swelling of austenitic steels at low dose rate. Information on swelling, grain boundary segregation, tensile properties [9] and microstructural irradiation behavior [10] of reactor structural materials has recently (2006) been obtained out of samples irradiated at $\sim 1-30$ dpa total dose in the EBR-II reactor, at temperatures from 371 to $440{ }^{\circ} \mathrm{C}$ and low dose rates (up to $5.810^{-7} \mathrm{dpa} / \mathrm{sec}$ ). The data corresponds to stainless steel hexagonal ducts that were used to house reactor subassemblies in the reflector region of the $20 \mathrm{MWe}$-Experimental Breeder Reactor II (EBR-II) that operated from 1963 to 1994 . These results complement the hundreds of neutron irradiation studies performed on austenitic stainless steels carried-out in the past 35 years. Low temperatures $\left(<350^{\circ} \mathrm{C}\right)$ and low doses $(<10 \mathrm{dpa})$ is a region where apparently there is a lack of systematic data.

Some metals are more intrinsically resistant to corrosion than others. Austenitic steels have proven to be unsatisfactory containment materials for liquid $\mathrm{Pb}$-alloys at temperatures above $500{ }^{\circ} \mathrm{C}[11]$. The reason for this is the high solubility of Ni in lead.

Experimental results obtained in [12] show that at $460{ }^{\circ} \mathrm{C}$, all US steels after $3000 \mathrm{~h}$ of tests appear to have satisfying performance. Three types of austenitic steel (316, 316-L, D-9) were investigated. At $460{ }^{\circ} \mathrm{C}$, these steels developed single-layer oxide films up to $3000 \mathrm{~h}$ of tests. At $550{ }^{\circ} \mathrm{C}$, double-layer oxide films formed on tube specimens made of 316 and D-9 steels, while only single-layer oxide film formed on rod specimens made of 316-L. The presence of double oxide layers protects the steels against dissolution. Note that, if the layers are too 
thick they might crack and spall and become unstable which is detrimental to the corrosion performance. Liquid metal corrosion was observed in $316-\mathrm{L}$ at $550{ }^{\circ} \mathrm{C}$ after $2000 \mathrm{~h}$.

Alloy 316-L resistance to heavy metal corrosion is not as good as the ferritic materials and therefore its use is restricted to temperatures less than $400-500^{\circ} \mathrm{C}$ in lead or lead-bismuth eutectic (LBE) facilities, depending on the oxygen control and the desired operation lifetime. The DELTA loop, an LBE test loop set up at the Los Alamos National Laboratory, has used 316-L extensively.

Like other materials exposed to high temperature lead and LBE, the key parameters to the materials performance are temperature, oxygen control and flow rate. With oxygen controlled at $10^{-6} \mathrm{wt} \%$ and the LBE flow $1 \mathrm{~m} / \mathrm{s}$ at $400{ }^{\circ} \mathrm{C}$, the oxide layer on the material may eventually grow to tens of microns thick (could take many years), while the long-term substrate recession rate is less than $1 / 10 \mathrm{micron} / \mathrm{yr}$. Performance life at these conditions for 316-L would be expected to be more than 30 years. At $450{ }^{\circ} \mathrm{C}$, the oxidation could also grow to 10 micron thickness or there about, the material loss rate could be a fraction of micron/yr at this temperature and $1 \mathrm{~m} / \mathrm{s}$ flow and the operational life may be something less than 30 years.

The material loss rate increases quickly as temperature rises. Also at higher temperature, break away oxidation may occur after a sufficiently long time, which is a lot faster than normal parabolic oxidation, and further clouds the ability to predict lifetimes.

At temperatures less than $480{ }^{\circ} \mathrm{C}, 1 \mathrm{~m} / \mathrm{s}$ or less and proper oxygen control, one could expect 316-L design life to be greater than 15 years and exceeding 30 years at $400{ }^{\circ} \mathrm{C}$, with a reasonable allowance for corrosion. From a cost and fabrication experience standpoint this material might be preferred for use for the vessel and other components of the LFR test demonstrator that are maintained at lower temperatures.

Newly developed materials, and new materials surface treatments are currently being investigated looking for better corrosion resistance properties (aluminized 316-L SS, shotpeened [13] and laser-peened 316 SS [14]).

The existing results indicate that for austenitic steels, the oxides are thin and not completely protective at $550{ }^{\circ} \mathrm{C}[15]$.

\section{$3.2 \quad H T-9$}

HT-9 is considered a Generation 1 steel [16]. These steels are based on simple Cr-Mo steels. Variations in their chemistries, in particular the addition of $\mathrm{Mo}, \mathrm{Nb}$, and $\mathrm{V}$, increased the rupture strength to $60 \mathrm{MPa}$ and extended the operating temperature range. HT-9 (12Cr$1 \mathrm{MoWV}$ ) has a broad database available, but as explained below has poorer properties than $\mathrm{T}-91(9 \mathrm{Cr}-1 \mathrm{MoVNb})$.

\section{Temperature and dose limits for swelling in HT-9 and T-91}


F/M alloys are the substitutes for austenitic steels fuel assembly (cladding \& wrapper) of advanced fast reactors. In F/M steels, swelling is low relative to other materials considered for nuclear application. Swelling is not expected to limit the use of the steels up to a service lifetime of $150-200 \mathrm{dpa}[17,18]$. At the maximum swelling temperature of $400{ }^{\circ} \mathrm{C}-420{ }^{\circ} \mathrm{C}$, less than $2 \%$ swelling was observed for HT-9 and modified 9Cr-1Mo (T-91) irradiated to 200 dpa in the Fast Flux Test Facility (FFTF) [19].

Swelling is defined as the percent change in volume $\square \mathrm{V} / \mathrm{V} 0$ after irradiation (V0 corresponds to the volume in the unirradiated condition). According to the current understanding, the lower swelling rate in $\mathrm{F} / \mathrm{M}$ steels $(0.2 \% / \mathrm{dpa})$, i.e. lower than that of austenitic steels austenitic steels $(\sim 1 \% / \mathrm{dpa})$, is has been attributed to the fact that austenitic steels have an fcc structure and void nucleation proves to be more difficult in the F/M bcc structure. These commonly held concepts have been reviewed recently [20]. It has been shown that the incubation period is much longer for $\mathrm{F} / \mathrm{M}$ steels especially when irradiated under wellcontrolled temperature conditions, (as in the case of FFTF experiments), but then these steels swell to at an accelerated rate of $\sim 0.2 \% / \mathrm{dpa}$ and possibly greater.

\section{Temperature and dose limits for creep resistance in HT-9 and T-91}

Although HT-9 and T-91 alloys have excellent swelling resistance (1\% swelling reported in HT-9 after irradiation at $420{ }^{\circ} \mathrm{C}$ for $200 \mathrm{dpa}$ ) their creep resistance decreases drastically above $500{ }^{\circ} \mathrm{C}$. The database available is scarce and has been obtained in the 70 's when high$\mathrm{Cr}(9-12 \mathrm{Cr} \%) \mathrm{F} / \mathrm{M}$ steels became candidates for elevated temperature applications in the core of fast reactors. HT-9 and T-91 steels were initially used as boiler components because they showed high $10^{5} \mathrm{~h} / 600^{\circ} \mathrm{C}$ creep-rupture strength (in the range of $60 \mathrm{MPa}$ for HT91 and 94 - $87 \mathrm{MPa}$ for T-91 [21]).

In the fast reactor program [22], HT-9 has shown to have adequate thermal creep properties to $650{ }^{\circ} \mathrm{C}$.

Larson-Miller diagrams for the results of creep rupture tests are reported in [23] for HT-9 and T-91, see Fig. 1. Creep-rupture strengths of HT-9 and T-91 steels decrease with increasing test temperature and time. T-91 shows a higher creep-rupture strength compared to HT-9. Selecting a cladding end-of-life (EOL) of 32 fpy ( 40 calendar years of operation at 0.8 loading factor), i.e. $\sim 280000 \mathrm{~h}$, yields limiting stresses of $41 \mathrm{MPa}$ at $622{ }^{\circ} \mathrm{C}$ for T-91 and only $15 \mathrm{MPa}$ for HT-9. A cladding made of T-91 could allow going higher in temperature by $20{ }^{\circ} \mathrm{C}$ and still keep the stress limited to max. $15 \mathrm{MPa}$. It should be noted that for cladding applications the operating lifetime is much lower than the $>300000 \mathrm{~h}$ foreseen for nuclear power plants. 
HT9 \& T91

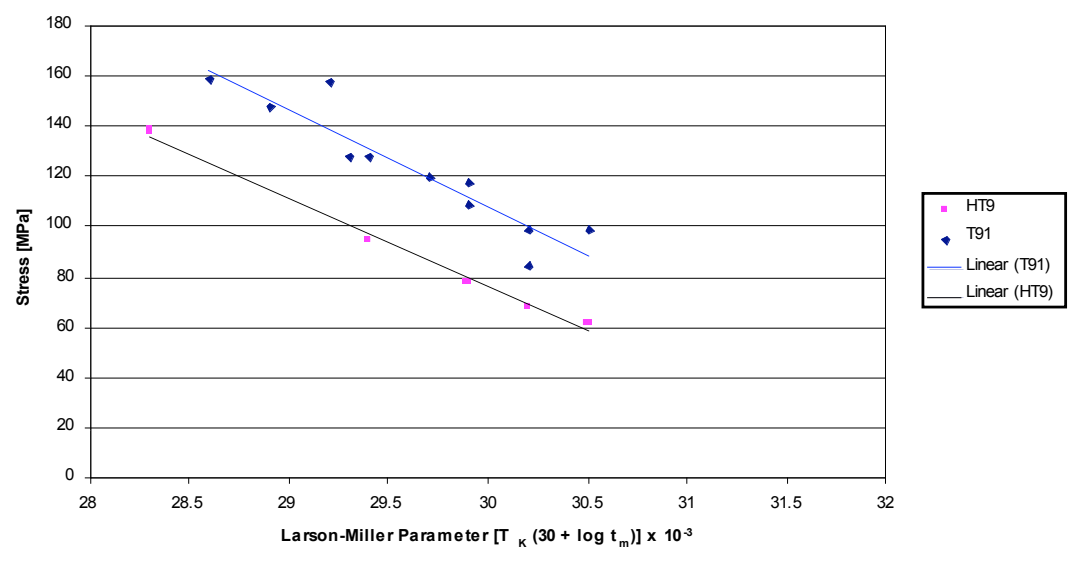

Fig. 1: Larson-Miller plot indicating a higher creep-rupture strength for T-91 compared to HT-9.

Modern steels, like F82H a reduced activation steels specifically developed for fusion [24] shows thermal creep strength superior to that of HT-9, see Fig. 2. F82H was planned as a reduced-activation modification of T-91, keeping mechanical properties within similar levels. Creep strength of F82H has been shown to be similar to that of T-91 [25].

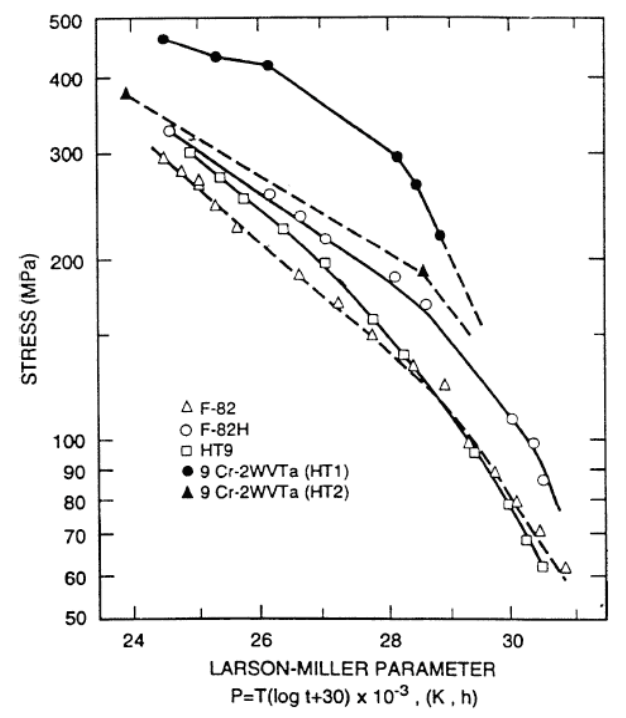

Fig. 2: Larson-Miller plot for HT-9 and several reduced activation martensitic steels.

Note that different creep mechanisms are responsible for the change in slope in the creeprupture plot. As reported in [26] a reliable thermal creep correlation for HT-9 is necessary to examine whether the design requirement for a long-term high temperature operation is met. The authors report that creep correlations have serious weaknesses in estimation of thermal creep behavior of HT-9 compared to measured creep data [26] and propose a new correlation that better fits the measured data. 
Advanced materials with better creep properties have been obtained by further optimizing the microstructure as shown by the results corresponding to two lab-heats named HT1 and HT2 in Fig.2.

\section{Low temperature radiation hardening in F/M steels}

\section{Embrittlement}

Ferritic-martensitic steels offer excellent high temperature strength, but are sensitive to irradiation-induced embrittlement at irradiation temperatures less than $\sim 450{ }^{\circ} \mathrm{C}$. Hardening and embrittlement effects tend to vanish as the irradiation temperature increases. The effect of irradiation temperature on the impact properties is illustrated in Fig. 3. DBTT increases as irradiation temperatures decreases for T-91 and HT-9 steels irradiated at Phenix up to similar values of neutron dose [27].

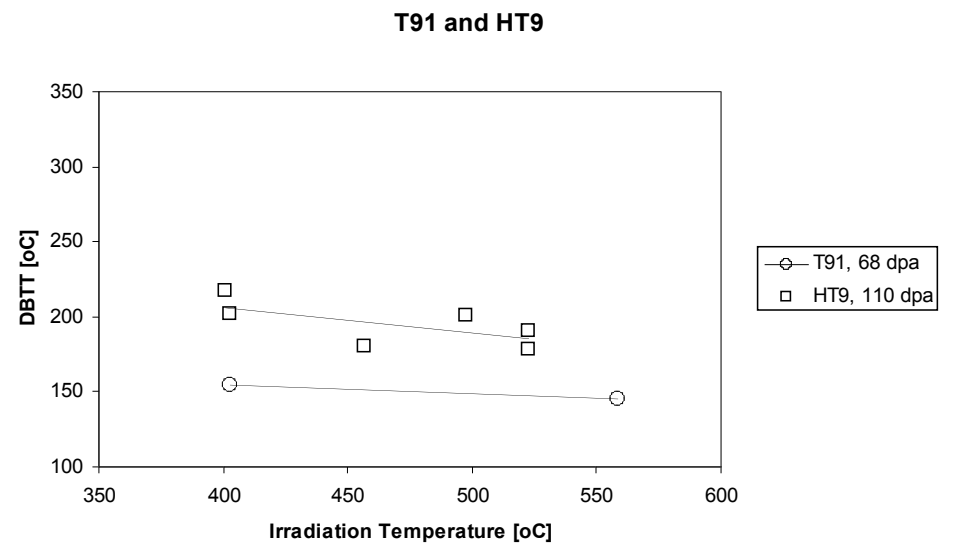

Fig. 3: Embrittlement increases as irradiation temperature decreases for both HT-9 (square) and T-91 (circle) steels irradiated to 68 and 110 dpa in Phenix.

Hardening (increase of tensile strength) and embrittlement, measured in terms of the shift of ductile-to-brittle transition temperature (DBTT) and decrease in the upper-shelf energy (USE), are more pronounced in HT-9 than in T-91 as expected on the basis of its higher $\mathrm{Cr}$ content.

A yield strength increase of $82 \%$ (69\%) was recently reported for HT-9, and T-91 irradiated at $200^{\circ} \mathrm{C}$ in BR2, SCK, Belgium up to a dose of $\sim 4.35 \mathrm{dpa}$ [28]. A DBTT shift of $\sim 163{ }^{\circ} \mathrm{C}$ was found when HT-9 was irradiated up to $3.7 \mathrm{dpa}\left(169^{\circ} \mathrm{C}, 2.47 \mathrm{dpa}\right)$ at $200{ }^{\circ} \mathrm{C}$ in BR2 reactor in SCK, Belgium (see, Fig. 4). Also, HT-9 shows a DBTT shift of $\sim 160{ }^{\circ} \mathrm{C}$ when irradiated up to $10 \mathrm{dpa}$ at $365^{\circ} \mathrm{C}$ in FFTF [3 Klueh]. 


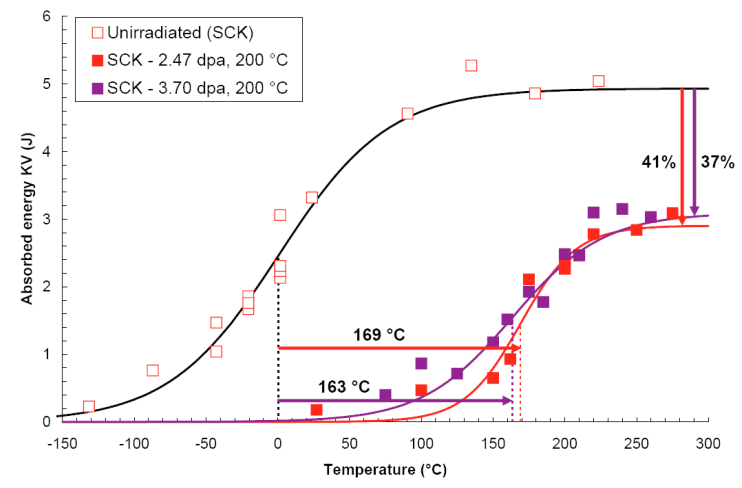

Fig. 4: Shift in DBTT obtained for HT-9 (12Cr-1MoVW) in the unirradiated and irradiated condition (SCK $200{ }^{\circ} \mathrm{C}, 2.47,3.70 \mathrm{dpa}$ ).

T-91 was also irradiated in the same experiment in BR2. As said before at $200{ }^{\circ} \mathrm{C}, \mathrm{T}-91$ showed a lower embrittlement than HT-9. A shift in DBTT of $\sim 131{ }^{\circ} \mathrm{C}$ was found for 3.58 dpa $\left(109^{\circ} \mathrm{C}\right.$ for 2.43 dpa), see Fig. 5.

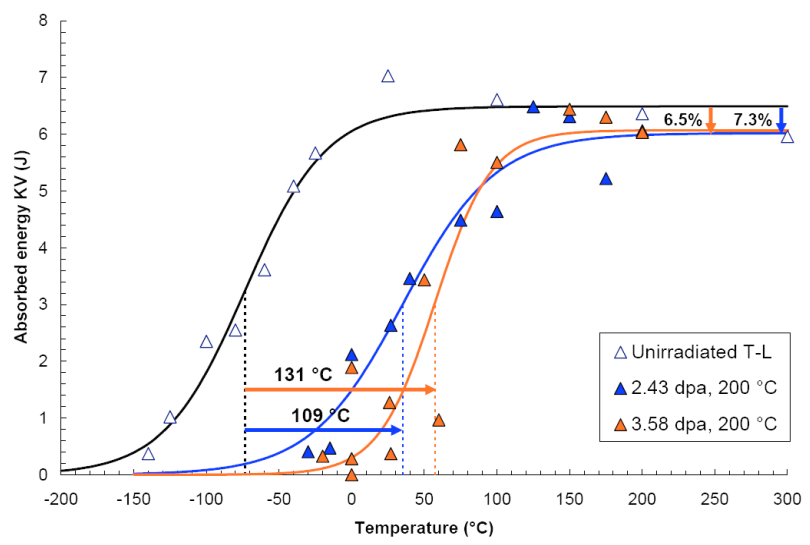

Fig. 5: Shift in DBTT obtained for T-91 (9Cr-1MoVNb) in the unirradiated and irradiated condition (SCK $200{ }^{\circ} \mathrm{C}, 2.43,3.58 \mathrm{dpa}$ ).

In general, 7-9Cr martensitic steels are considered better than those with higher (10-13 wt.\%) chromium contents because of their lower ductile-brittle transition temperature (DBTT) shifts after irradiation.

In Fast Flux Test Facility (FFTF) [29], T-91 (triangle) showed better embrittlement properties than HT-9 (circle). A very low transition shift $\square$ DBTT $\sim 45^{\circ} \mathrm{C}$ was reported for T91 when irradiated up to $\sim 5$ dpa at $365^{\circ} \mathrm{C}$, see Fig. 6 . 


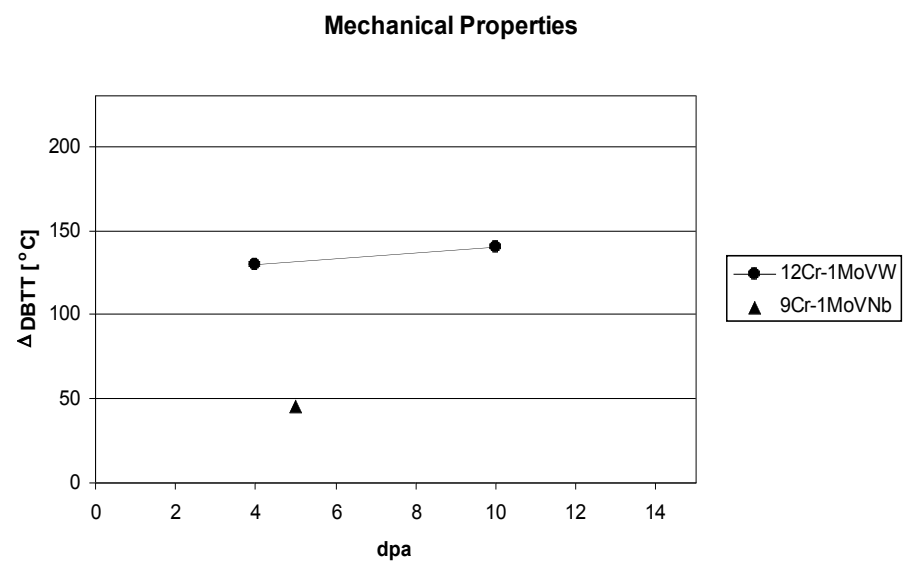

Fig. 6: Ductile-to-brittle transition temperature shift as a function of neutron dose for $12 \mathrm{Cr}$ $1 \mathrm{MoW}$ (circle) and $9 \mathrm{Cr}-1 \mathrm{MoVNb}$ (triangle) steels. Irradiations carried out at FFTF at $\mathrm{T}_{\text {irr }}=$ $365^{\circ} \mathrm{C}$.

Fig. 6 also shows that, at a given temperature, embrittlement increases as a function of dose measured; in this case in terms of dpa. This is illustrated in Fig. 7 where the T-91 trend curve derived in AAA Materials Handbook Ch. 19 is shown. The results recently obtained in BR2 reactor in SCK, Belgium for T-91 irradiated at $200{ }^{\circ} \mathrm{C}$ (yellow circles) compare well with those reported in the Handbook [28]

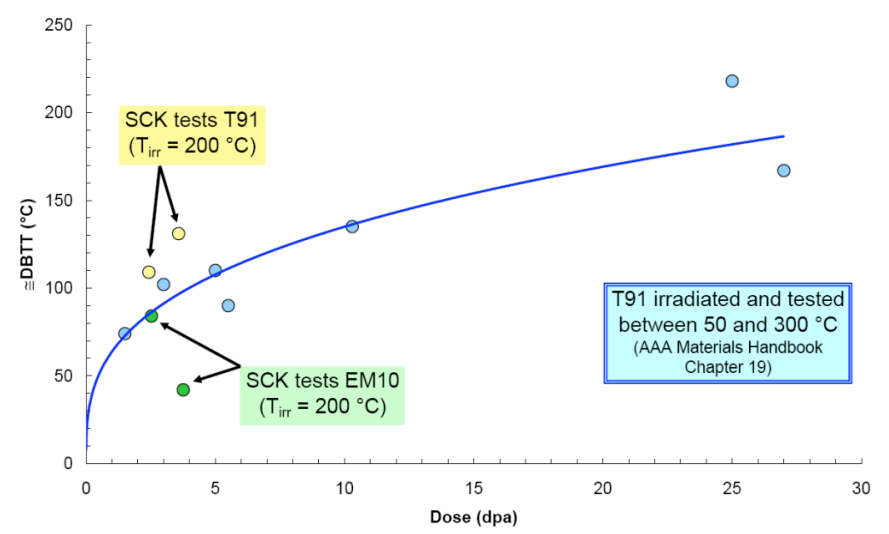

Fig. 7: Ductile-to-brittle transition temperature shift as a function of neutron dose for $12 \mathrm{Cr}-$ $1 \mathrm{MoW}$ (circle) and $9 \mathrm{Cr}-1 \mathrm{MoVNb}$ (triangle) steels. Irradiations carried out at FFTF at $\mathrm{T}_{\text {irr }}=$ $365^{\circ} \mathrm{C}$.

\section{Corrosion in HT-9, T-91, EP-823}

Liquid lead and the eutectic lead-bismuth alloy (LBE) are considered as possible coolants of the LFR reactor. Because of the high solubility of iron in lead, ferritic-martensitic steels get easily corroded in both pure lead and LBE. One way of reducing the strong corrosion is the in-situ formation of stable oxides on the steel surfaces, see Fig. 8. 


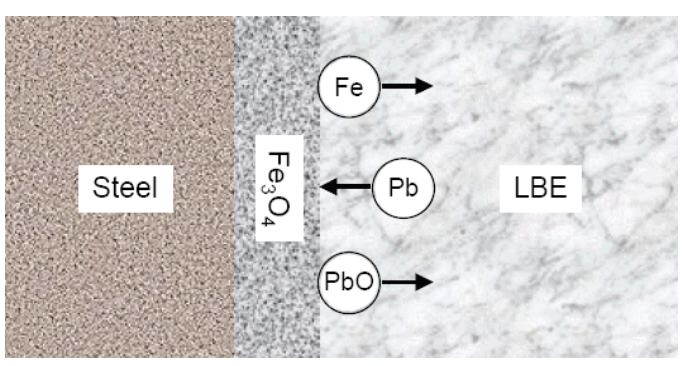

Fig. 8: "Self-healing” oxide formed on steel by adjusting oxygen potential in LBE [30].

The means to generate and maintain a protective oxide coating have been demonstrated at the laboratory level [31]. International LBE/Pb Corrosion test results (mostly for $3000 \mathrm{hr}$ or less) have shown [30] that with oxygen control $\left(\sim 10^{-6} \mathrm{wt} \%\right.$ in LBE):

- 316 L type austenitic steels, and T-91, HT-9 type ferritic/martensitic steels can be protected up to $\sim 550{ }^{\circ} \mathrm{C}$

- $\quad$ At $\sim 600^{\circ} \mathrm{C}$, oxide cannot protect austenitic steels

- $\quad$ Oxide on most $\mathrm{F} / \mathrm{M}$ steels may grow too thick for long-term use at $\sim 500^{\circ} \mathrm{C}$ or higher

$\mathrm{O}_{2}$-control techniques use sensors to measure the level of oxygen dissolved in lead or LBE. Experimental tests have been performed at LANL [31] that show acceptable corrosion rates for EP-823 exposed to flowing LBE at $535^{\circ} \mathrm{C}$ for 600 hours. EP-823 is one of the corrosion resistant materials developed in Russia for use in LBE-cooled reactors.

These tests have also shown that between $550-600{ }^{\circ} \mathrm{C}$, the formation of protectiveness of oxides on martensitic steels are uncertain for durations up to a few hundred hours, but usually fail after that. In particular, HT-9 develops a double layer of oxides after $1000 \mathrm{~h}$ in flowing LBE at $\sim 450{ }^{\circ} \mathrm{C}[32]$. The oxides are relatively thick indicating that HT-9 may not be suitable for long-term uses due to cracking and spalling of structurally unstable thick oxides. A group in Forschung Zentrum Karlsruhe-FZK (Germany) and Centre d'Etudes AtomiquesCEA (France) are studying Fe/Al-based coatings for corrosion protection. Surface treated steel (shot-peened, laser peened HT-9) could also show promise [15] and tests are currently being performed at LLNL to study [14] the effect of high temperature on the induced LP residual stress.

For the conventional (out-of core) components like coolant piping/guides the operational design data corresponds to low fluence level, medium pressure levels, moderate working temperature range $350-550{ }^{\circ} \mathrm{C}$. For these conditions, ferritic/martensitic $9-12 \% \mathrm{Cr}$ steels like HT-9, T-91 are used today [33]. In this case, the corrosion behavior as function of temperature and $\mathrm{Cr}$ content is of importance. In [34] it is shown that alloys with high $\mathrm{Cr}$ content are more corrosion resistant to $\mathrm{LBE}$, but also the $\mathrm{Cr}$ content effectiveness decreases at temperatures of $500{ }^{\circ} \mathrm{C}$. The corrosion rate of $12 \mathrm{Cr}$ steel estimated in [34] is a few $\square / \mathrm{y}$ at $400{ }^{\circ} \mathrm{C}$.

The lower temperature limit is imposed by melting points for lead $\left(327^{\circ} \mathrm{C}\right)$ and LBE $(125$ ${ }^{\circ} \mathrm{C}$ ) as shown in Fig. 9. The solid and dashed lines represent the technological limits extrapolated from the European experience on LBE [35]. The graph shows the thermal cycle proposed for the ELSY, a lead-cooled fast reactor that follows a European concept proposed 
by Gen-IV partners. Both concepts, ELSY and SSTAR, have low vessel operating temperatures $\left(400{ }^{\circ} \mathrm{C}\right.$ for ELSY and $420^{\circ} \mathrm{C}$ in the case of SSTAR). This reduces the significance of embrittlement, a major concern in the region below $400{ }^{\circ} \mathrm{C}$.

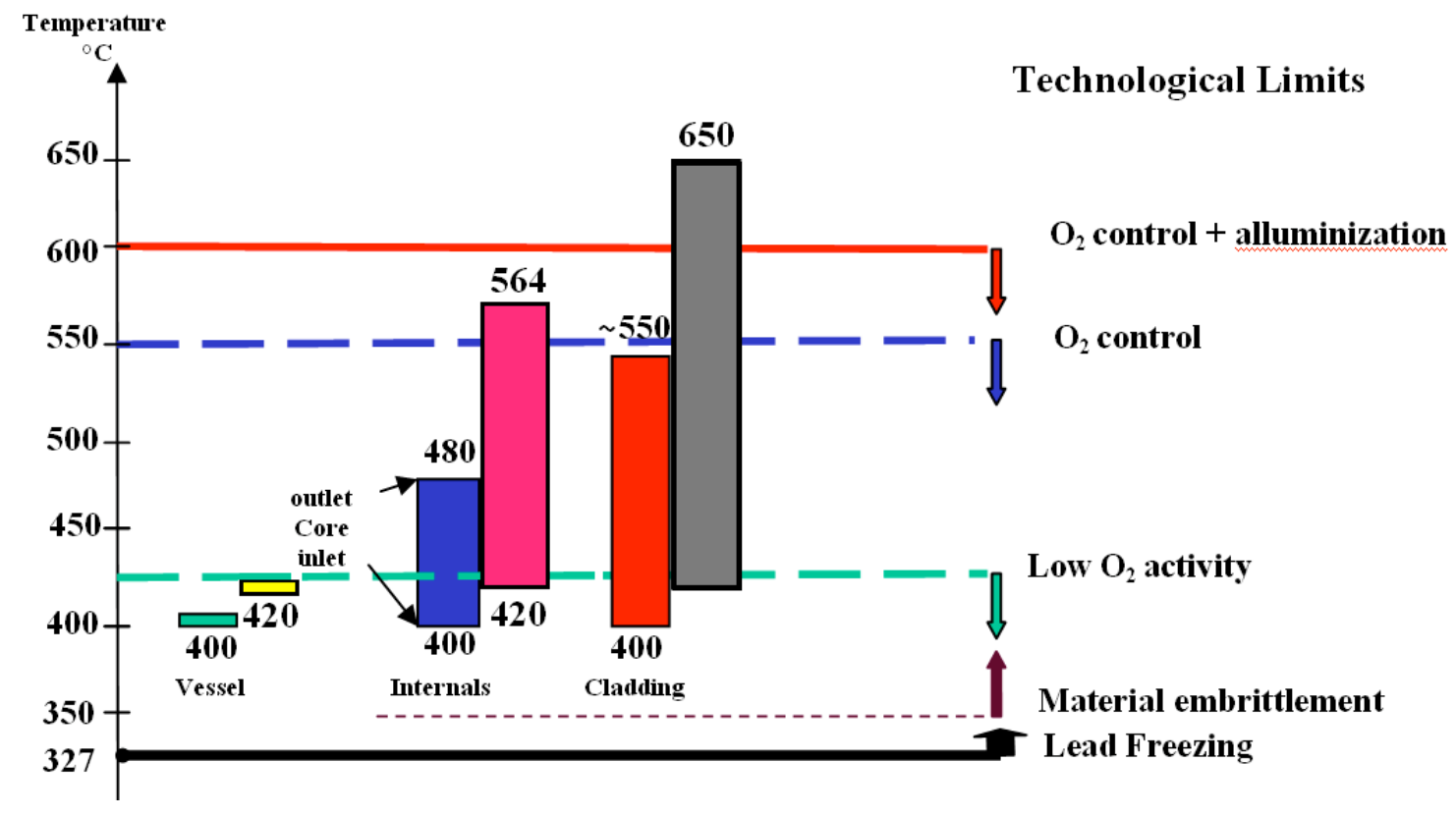

Fig. 9: Technological limits and thermodynamic input for SSTAR and ELSY

Low core outlet temperatures $\left(480^{\circ} \mathrm{C}\right)$ have been proposed for the ELSY. The cladding is the key component affected by corrosion and imposes the high temperature technological limit in both cases. Controlled oxygen activity has been suggested for temperatures up to $550^{\circ} \mathrm{C}$. Alluminization of the steel (Fe/Al-based coatings) could extend the upper temperature limit to $600{ }^{\circ} \mathrm{C}$ in $\mathrm{LBE}$

\section{$3.3 \quad T-91$}

Further optimization of the $\mathrm{C}, \mathrm{Nb}$, and $\mathrm{V}$ contents of these first generation steels lead to steels with rupture strength $(100 \mathrm{MPa})$ and higher operating temperatures $\left(593^{\circ} \mathrm{C}\right)$. T-91 belongs to this group together with $\mathrm{HCM} 12$ and $\mathrm{HCM} 2 \mathrm{~S}$. There $12 \mathrm{Cr}$ variants offer improved properties relative to HT-9. For example, the HCM 12A alloy has a good database and is currently approved by ASME Code Case 2180 to $649{ }^{\circ} \mathrm{C}$ for application in Sections I and VIII [36].

T-91 can be considered a Generation 2 steel. It is a modified high temperature $9 \mathrm{CrMoVNb}$ steel used in conventional nuclear and non-nuclear industries. This class of materials has the most industrially mature high strength database [36]. For example, the $9 \mathrm{Cr}-1 \mathrm{Mo}-\mathrm{V}$ (grade 91) alloy is ASME Code approved to $649^{\circ} \mathrm{C}$ for Section III, Classes 2 and 3 components and is in the final stages of approval for inclusion in Subsection NH for Class 1 applications. 
The potential of these structural materials for application in fuel cladding, core structures and out-of-core components has yet to be defined. Generation 1 F/M steels like HT-9 will be retained for the conventional parts of the LFR plant. For these steels a broad materials properties database already exists including their corrosion behavior [37], where a lifetime of 20 years $(\sim 200000 \mathrm{~h})$ might be considered. Protectiveness and stability of the oxides and long-term corrosion resistance are likely to be correlated, therefore in [37] it is recommended that promising candidates be tested for long durations to validate their long-term performance. This is an area where LFR R\&D is needed.

These F/M materials can operate in a LBE environment at temperatures of $550{ }^{\circ} \mathrm{C}$ with a refuel plan that considers a service lifetime much less that the $>300,000 \mathrm{~h}$ envisioned for SSTAR. It is assumed that the fuel will be designed for 160,000 hours of effective full power operation ( $\sim 44$ days). The reactor outlet temperature will be less than $450{ }^{\circ} \mathrm{C}$, i.e. a cladding temperature of $\sim 550^{\circ} \mathrm{C}$.

Generation 2 steels, like T-91, should be the choice for in-core-materials and cladding. The assessment here is less clear. We have to take in account the existing experimental investigation on irradiation effects like swelling and irradiation creep. We underline that it is of the highest priority to extend the current R\&D work in this area.

\section{$3.4 \quad E P-823$}

EP823 is a Russian developed ferritic steel that has been used extensively in their LBE cooled reactors. This material has properties similar to HT-9 but includes more Si which improves its corrosion resistance. Russia has an 80 reactor-year experience with lead/bismuth eutectic (LBE) cooling in their Alpha submarines.

If it were possible to obtain both quality data and a qualified Russian supplier this may be an excellent choice for cladding and other core structures in a test reactor. A supplier of quality material has not been identified and development of a similar U.S. supplier and properties data could not be completed in a time frame consistent with near-term development of a test reactor.

F/M steels compatibility with LBE, has been extensively studied in Russia. Russia has experience with development of corrosion resistance techniques. The Russian alloy EP-823 was designed for low temperature lead-cooled reactors. A similar alloy could be used in the U.S. LFR test demonstrator although, as said above no manufacturing capability currently exists. EP-823 (0.18C-11.4Cr-0.5Ni-0.7Mn-1.1Si-0.6Mo-0.8W-0.4V-0.4Nb) has a higher concentration of Si than HT-9 (0.25\%). Mechanical properties of Russian steels EP-450 and EP-823 have been reported [38]. EP-450 (similar to HT-9) is well-characterized and has proved to be rather more brittle than EP-823. EP-823 has an improved corrosion resistance due to a higher Si content ( $\sim 1.1 \%$ compared to $\sim 0.2 \mathrm{wt} \%$ in EP-450).

EP-823 was successfully used as fuel pin cladding in an experimental assembly irradiated in the BOR-60 fast reactor. The pins were irradiated in the $300-680{ }^{\circ} \mathrm{C}$ range to a maximum dose of $63 \mathrm{dpa}$ and showed no significant changes in mechanical properties above $450{ }^{\circ} \mathrm{C}$ [39]. Also, EP-823 specimens were irradiated in BR-10, BN-600 and BN-350 at temperatures 
300-500 ${ }^{\circ} \mathrm{C}$ and doses 10-30 dpa. Post-irradiation tests of these specimens have not been conducted yet [40]. The radiation resistance of EP-823 needs to be further investigated.

These samples represent an enormous wealth of information on tensile properties of EP-823. Testing these tensile specimens will further the investigation on the effect of Si content and provide useful data at irradiation temperatures (above and below $450{ }^{\circ} \mathrm{C}$ ) where significant differences in the materials behavior were found in former investigations.

Recently, EP-823 and EP-450 demonstrated compatibility with nitride fuel and lead in the SM-2, BR-10, BOR-60 reactors. There it was shown that mononitride fuel (U0.9-0.85Pu0.1$0.15 \mathrm{~N}$ ) interacts neither with lead nor with the cladding steels EP-823 and EP-450 at the temperature of 650 and $800^{\circ} \mathrm{C}$ for up to 2000 hours (the measurement time) and at the temperature of 1200 and $1300^{\circ} \mathrm{C}$ (chosen for the simulation of emergency situations) for 5 hours [41]

\section{Development of Advanced Materials}

New reduced activation alloys that substitute Mo by $\mathrm{W}$ as the main solution hardening element, without $\mathrm{Nb}, \mathrm{Ni}$ and other radiologically undesirable elements, led to a generation of experimental alloys that are currently being investigated for fusion structural applications (F82H, JLF1, EUROFER) [42-44].

Further steel developments with the addition of $\mathrm{Cu}$ or Co showed increased the rupture strength to $180 \mathrm{MPa}$ and could extend the operating temperature range to $650{ }^{\circ} \mathrm{C}$ (HCM12A, NF616, E911, NF12, SAVE12, etc.) [16]. Oxide Dispersed Steels (ODS MA956, 12Y, 12YWT) have shown remarkable high-temperature creep properties but need further improvements (microstructure homogeneity, isotropic mechanical properties, joining and fabrication issues) [45].

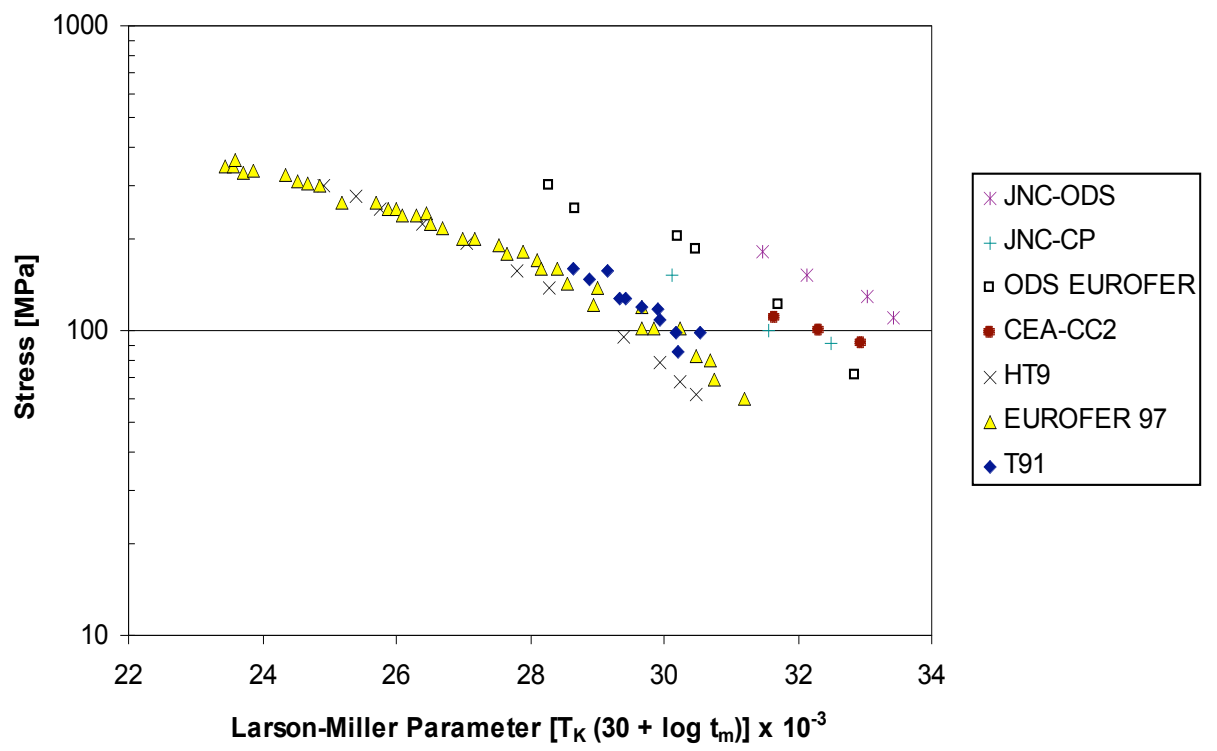

Fig. 10: Larson-Miller curve for $\mathrm{T} 91$ (mod. $9 \mathrm{Cr}-1 \mathrm{Mo}$ ) as compared to other $\mathrm{F} / \mathrm{M}$ steels. 
Fig. 10 shows results published in 2004 by Ukai et al. [46] of creep rupture tests of JNC-CP and CEA-CC2 claddings obtained at $700{ }^{\circ} \mathrm{C}$, using internally helium gas pressurized specimens in the hoop stress range $90-150 \mathrm{MPa}$ and rupture times up to $7000 \mathrm{~h}$. JNC-CP, CEA-CC2 type of cladding exhibit similar strength levels and the same trend of hoop stress vs. rupture time. JNC-ODS shows that ODS F/M alloys option could be retained for LFR materials matrix since it could extend the cladding operating temperature to $\mathrm{T} \sim 800{ }^{\circ} \mathrm{C}$ [47]. ODS materials seem to offer greater strength at temperatures above $600{ }^{\circ} \mathrm{C}$. This is shown in Fig. 11 where ODS MA957, 12Y1 and 12YWT creep resistance are compared with that of a commercial $\mathrm{F} / \mathrm{M}$ steel $9 \mathrm{Cr}-\mathrm{WMoVNb}$.

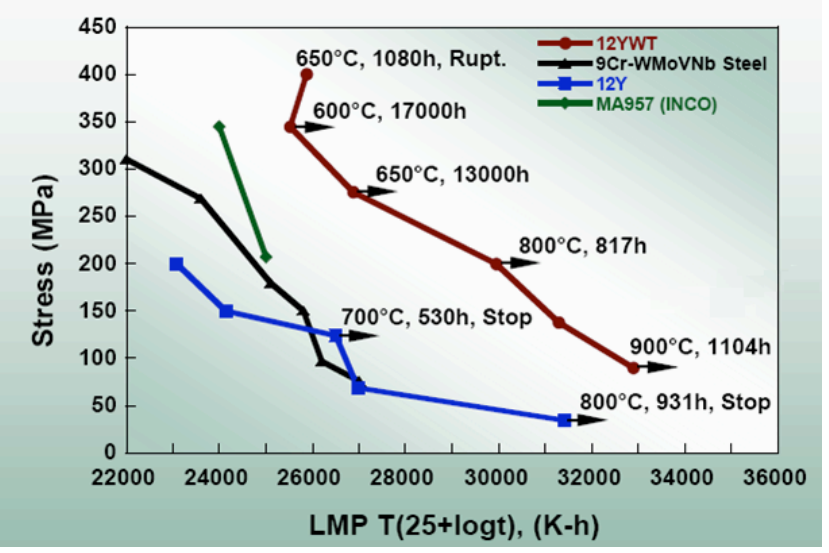

Fig. 11: Larson-Miller diagram for the creep-rupture strength of four ODS steels and a conventional ferritic/martensitic steel. The arrows indicate that the test is still in progress or it was discontinued prior to rupture.

ODS steel MA957 (Fe-14Cr-03.Mo-0.9Ti+0.25 $\left.\mathrm{Y}_{2} \mathrm{O}_{3}\right)$ having greater strength was developed by the International Nickel Company (INCO) [47]. MA957 is a $14 \mathrm{Cr}$ ferritic steel strengthened with a fine dispersion of $\sim 5 \mathrm{~nm}$ yttrium oxide particles. This steel together with MA956 (Fe-19Cr-0.33Ti-5Al-0.4Y-0.15O-0.02C) are commercial ODS steels.

ODS 12YWT (MA Fe-12Cr-3W-0.4Ti + Y2O3) alloy exhibits excellent high temperature creep strength superior to the other materials (see the upper curve in Fig. 11). Note that in this case $\mathrm{LMP}=\mathrm{T}(25+\log \mathrm{t})$.

Concerning irradiation creep, recently (2004) MA957 alloys have been shown to have better creep resistance than traditional $\mathrm{F} / \mathrm{M}$ steels above $550{ }^{\circ} \mathrm{C}$ [48]. The temperature dependence of irradiation creep compliance of MA957 and HT-9 during irradiation is reported in [48], see Fig. 12. There we see that at $600^{\circ} \mathrm{C}$ the creep compliance increases while that of MA957 is roughly independent of temperature. 




Fig. 12: Temperature-dependent irradiation creep compliance of MA957 and HT-9 during irradiation.

These are again results that were obtained from PIE of FFTF samples emphasizing the worth of that database. In fact, we note that only a limited amount of information is currently available concerning the stability of oxide particles in ODS ferritic steels under neutron irradiation. Two experimental ODS ferritic alloys were irradiated in JOYO [49]. No irradiation experiments have been done to study the irradiation behavior of 12YWT alloy yet. Only one study using 3.2 MeV Fe+ion irradiation with simultaneous He injection has been performed [50].

R\&D in advanced materials (ODS, Al-coating, surface treatments, etc.) shows a promising avenue. 9Cr-ODS (oxide dispersion strengthened) steels are being developed for structural materials of fast breeder reactors and fusion reactors. These steels are characterized by small Y-Ti-O complex oxide particles dispersed in the matrix. Microstructural evolution during creep of 9Cr-ODS steels has been recently reported [51]. The use of an anti-corrosion coating layer on steel surface is a promising means to provide corrosion protection at elevated temperatures $\left(>500^{\circ} \mathrm{C}\right)$. In fact, preliminary investigations have successfully demonstrated the feasibility of such coatings: alumina-coated steel immersed in molten lead at a constant temperature of $520^{\circ} \mathrm{C}$ have shown significantly improved surface stability [52]. Alumina could be a promising coating material. It has been shown that it protects conventional F/M 9$12 \% \mathrm{Cr}$ steels in corrosive environments. In 2005 [53], results on corrosion resistance at 650 ${ }^{\circ} \mathrm{C}$ of aluminide coatings applied on coated samples $9 \% \mathrm{Cr}$ steel $\mathrm{P} 91$ and the $12 \% \mathrm{Cr}$ steel HCM12A, showed better resistance to corrosion than the uncoated material.

Other surface treatments as laser peening have recently been considered. Preliminary promising results from a corrosion test have shown laser peening (LP) might help the steel resist the formation of oxide layers. At LLNL T-91, HT-9, EP823 and 316-L samples were laser peened and sent to the corrosion DELTA loop at LANL. Results indicate that HT-9 and T-91 have the same behavior. EP83 shows the best performance. The Material Performance group at UC Davis is currently performing residual stress on similar samples that underwent different heat treatments up to $650{ }^{\circ} \mathrm{C}$. Slitting and $\mathrm{x}$-ray diffraction (XRD) will provide information about the surface stresses. Further studies are envisaged to understand the mechanisms that are operating. 
EM10 is an advanced experimental steel. Recently, (2005) the embrittlement response of EM10 has been obtained at low temperature $\left(T=200{ }^{\circ} \mathrm{C}\right)$ showing better impact properties than T-91 in the same irradiation condition.

EM10 is a 9Cr-Mo steel that differs from T-91 in that it is not stabilized with niobium and vanadium (it contains no niobium and only $0.03 \% \mathrm{~V}$ compared to $0.06 \% \mathrm{Nb}$ and $0.25 \% \mathrm{~V}$ for T-91). EM10, together with F82H, and EUROFER97, have also been extensively investigated as possible candidates for the internal structures of Gen-IV reactors. All these materials suffer from radiation hardening and embrittlement below $400{ }^{\circ} \mathrm{C}$, even at moderate doses $(\sim 1 \mathrm{dpa})$. The reason for this lies in the radiation-induced microstructural changes. In recent small angle neutron scattering (SANS) studies, after neutron irradiation (0.7-2.9 dpa between 250 and $400{ }^{\circ} \mathrm{C}$ ), [54] the evolution of microstructure and its relationship with the degradation of mechanical properties was analyzed for HT-9, T-91, EM10, F82H, LA13T, LA12TaLC, La12LC, La4Ta, and Manet II.

It was shown that when the $\mathrm{Cr}$ content of the b.c.c. ferritic matrix is larger than a critical threshold value $\left(\sim 7.2\right.$ at.\% at $\left.325{ }^{\circ} \mathrm{C}\right)$, the ferrite separates under neutron irradiation into two isomorphous phases, Fe-rich $(\square)$ and Cr-rich ( $\left.\square^{\prime}\right)$. The authors conclude that for the Cr-rich materials (as is the case of HT-9), a significant contribution to the yield stress increase comes from the precipitation of the $\square$ ' phase. The quantity of precipitated $\square$ ' phase increases with the $\mathrm{Cr}$ content, the irradiation dose, and as the irradiation temperature is reduced. It is not observed in the case of the low $\mathrm{Cr}$ content F82H steel irradiated 2.9 dpa at $325^{\circ} \mathrm{C}$, where $\square$ ' phase does not form. Here, the main hardening contribution seems to be due to radiationinduced point defects clusters. A better understanding of the mechanisms involved in the phase transformation at the nanometer is needed to derive a correlation with chemical composition or microstructural parameters.

\section{Advanced modeling of nuclear materials}

Understanding the reasons for different response of different materials is crucial to the development of radiation-resistant materials for future advanced fission reactors. Ferritic steels are of interest because of their good thermal creep resistance and high threshold for swelling. Low temperature embrittlement at low temperature is a major drawback. The suitable temperature operation window for these steels is therefore fairly small, located between 350 and $550{ }^{\circ} \mathrm{C}$. A major contributor to the degradation performance is the formation of Cr-rich clusters under irradiation. The mechanisms for formation of such clusters under irradiation conditions was until recently not possible to model on an atomistic scale, due to the lack of empirical potentials for the Fe-Cr system valid over the entire range of chromium concentrations. At LLNL, we have developed an interatomic potential that correctly describes the thermodynamics of the system. This work is part of the on-going LDRD-ER “Critical Issues on Materials for Gen-IV Reactors” [55].

Prediction of how these materials will perform under high exposures (radiation induced swelling, hardening and embrittlement) represents a challenge to the capabilities of present day available models. Multiscale modeling, i.e. modeling of materials at several interconnected length and time scales (together with experimental verification) is a powerful 
approach that can provide advanced materials solutions to this and other critical issues on materials for Gen-IV reactors. The behavior of $\mathrm{Fe}-\mathrm{Cr}$ alloys under irradiation is in part controlled by the characteristics of point defects generated by high energy collision. Radiation enhanced diffusion and radiation induced precipitation are among the mechanisms that lead to changes in the microstructure under irradiation, and thus controlling effects such as swelling and $\square$ ' precipitation. Point defects in $\mathrm{Fe}-\mathrm{Cr}$ alloys are diverse in nature due to their interaction with a variety of local solute configurations. Ab-initio results indicate that the magnetic structure of the alloy is critical in determining this energetics. The ability to model these properties with classic potentials is still to be proven. At LLNL we are performing a detailed comparison between ab-initio and classic values of a variety of point defects configurations, testing in this way the extent to which classic potentials can be reliable used for radiation damage studies [56].

At LLNL, we are working in the development of a unified approach to multiscale materials modeling for nuclear applications based on sound theoretical considerations. This unified approach consists of a parameter-free computational methodology that provides insights into the mechanical and thermodynamic behavior of alloys under irradiation by linking tools at the atomistic scale with the corresponding mesoscale models. The numerical simulation of the mechanical properties of F/M irradiated steels highly depends on the selection of the $\mathrm{FeCr}$ interatomic potential. This is difficult because ferritic steels have an open (body centered cubic) crystalline structure and are ferromagnetic. Bonding in bcc metals have some covalent character that is not properly described in classic potentials, and additionally, point defect properties (like formation energies of the various interstitials) depend on the magnetic structure that is neither included in the potentials. Because of these complications, practically all the modeling data generated for steels is produced for idealized pure Fe with atomic potentials that do not even reproduce all the characteristics of the perfect system; in particular, they do not have the allotropic bcc-fcc transition at high temperature. We are developing a formalism that is able to use a new generation of classic potentials that account for the thermodynamic properties of the system [57-59]. This is a step forward to accomplish the objective of explaining the mechanisms responsible of the performance of neutron irradiated steels.

Is it possible to develop materials that are more tolerant to neutron-induced swelling? Theoretical understanding of the mechanisms that are responsible for swelling remains on a qualitative level [60].Multi-scale modeling of materials (MMM) is required to quantify the analysis. In the early 90's, Molecular Dynamics (MD) simulations in pure metals [61-63] have shown the formation of self-interstitial atoms (SIA) clusters directly in displacement cascades. In 2006, it has been shown for the first time that in bec FeCr alloys, that the SIA cluster diffusivity depends on $\mathrm{Cr}$ concentration and correlates with swelling [malerba]. The addition of small quantities of $\mathrm{Cr}(<10 \% \mathrm{Cr})$ strongly decreases swelling typically by an order of magnitude [64-66]. The alloy shows a tendency to order at these low $\mathrm{Cr}$ concentrations at temperatures of $400-500^{\circ} \mathrm{C}$. Swelling remains low for alloys with $\mathrm{Cr}$ concentrations between $1-10 \% \mathrm{Cr}$ and then rises again. For alloys with $\mathrm{Cr}$ concentration above $10 \%$, swelling has a local maximum and then decreases towards a quasi-asymptotical minimum which is attributed to precipitation of the Cr-rich $\square$ ' phase. The region of importance for nuclear applications is that of low $\mathrm{Cr}$ concentrations $[6-12 \% \mathrm{Cr}]$. The 
investigations reported indicate that the strong reduction in the SIA cluster mobility is the major reason for the reduced swelling rate in $\mathrm{Fe}-\mathrm{Cr}$ alloys. This is a matter still under discussion.

Development of advanced materials with better creep properties requires comprehensive understanding of the micromechanism involved. The different behavior of steels can be attributed to different chemical composition, and microstructural evolution. At a given stress, differences in dislocation density, the evolution of precipitates and solutes in the steel matrix determine the rupture life. Outstanding thermal creep resistance properties are obtained for oxide dispersion strengthened-ODS ferritic extending the operating temperature window up to temperatures of $800{ }^{\circ} \mathrm{C}$. Substantial information is still missing on their performance under irradiation. The possibility of irradiating under fully representative conditions in a fast fission reactor like the future Test Advanced Burner Reactor (TABR), foreseen to be in operation by 2019, will help establish the viability of using several new developmental steels in future commercial Gen-IV reactor designs.

\section{Selection of Materials for Early Demonstrator}

Development of a near-term LFR test demonstrator in the next 10 years appears to be achievable using existing materials technology and a core outlet temperature limited to about $450{ }^{\circ} \mathrm{C}$.

The LFR test demonstrator will rely on lead-bismuth as coolant. Material corrosion in leadbismuth is a major challenge for the initial LFR concept. Several test campaigns in the DELTA loop have shown that candidate materials 316-L, HT-9, T-91, and EP-823 can stand corrosion at temperatures below $550{ }^{\circ} \mathrm{C}$ if effective oxygen control is provided. Tests conducted at $535^{\circ} \mathrm{C}$ for $600 \mathrm{~h}$ show that EP-823 develops a thin and stable protective oxide coating when exposed to LBE flowing at $\sim 1 \mathrm{~m} / \mathrm{s}$. Both HT-9 and T-91 show similar performance. In both cases, oxides are generated and maintained but they are too thick and might spall which limits their long-term use in the reactor. 316-L developed a too thin oxide layer which might not be able sufficient to protect the material from corrosion in long-life applications. Significant R\&D is required for demonstration of coolant compatibility of a wide array of advanced structural materials, like ODS (MA956, MA957, PM2000, 12YWT, 14 YWT), and surface treatments, like laser peened austenitic and ferritic martensitic steels, that were explored for corrosion resistance enhancement at higher temperature and longer times. Clearly, to further develop the oxygen technology we need to demonstrate the corrosion behavior of these materials at the engineering scale where longer cycles $(>18,000$ h) and larger coolant flows are necessary.

However, the LFR test demonstrator design with 316-L, HT-9, T-91 and EP-823 steels is possible at lower temperatures. If we assume that the peak cladding temperature remains below $550{ }^{\circ} \mathrm{C}$, and the average core outlet temperature $430-450{ }^{\circ} \mathrm{C}$, we are below the technological limit of oxygen control and it is still possible to handle the corrosion problems. In this stage, the most significant demand is placed on mechanical properties of structural materials. Swelling and creep will set up the upper operating temperature limit for the cladding material, see Fig. 13. 


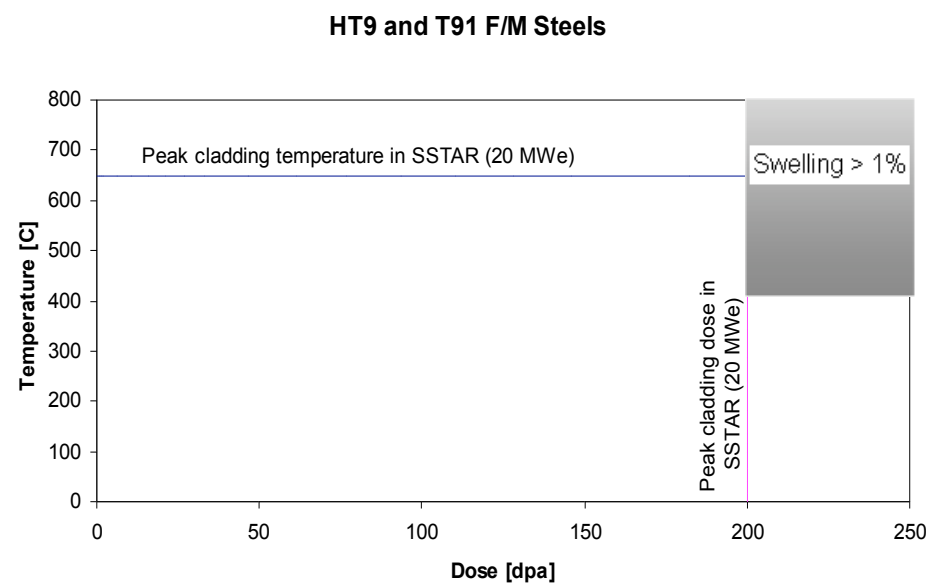

Fig. 13: Schematic diagram depicting the region where swelling could be considered a problem in LFR.

The ferritic-martensitic steels HT-9 and T-91 developed and tested within the US fast reactor programs have shown good swelling resistance at doses below $100 \mathrm{dpa}$. As mentioned in Section 3, swelling is not expected to limit the use of the steels up to a service lifetime of 150 -200 dpa $[17,18]$. At the maximum swelling temperature of $400{ }^{\circ} \mathrm{C}-420{ }^{\circ} \mathrm{C}$, less than $2 \%$ swelling was observed for HT-9 and modified 9Cr-1Mo (T-91) irradiated to 200 dpa in the Fast Flux Test Facility (FFTF) [19].

Transient conditions must be analyzed to show that the fuel cladding resists the internal pressure due to fission product generation. Advanced clad and wrapper materials with higher temperature strength and creep resistance will allow to attain in the future higher burn-up targets $(\sim 200 \mathrm{GWd} / \mathrm{t})$. Eventually, high temperature versions of the conventional alloys will be developed; like ODS that show very good creep resistance at temperatures above $800{ }^{\circ} \mathrm{C}$.

Although HT-9 and T-91 alloys have excellent swelling resistance (1\% swelling reported in HT-9 after irradiation at $420{ }^{\circ} \mathrm{C}$ for $200 \mathrm{dpa}$ ) their creep resistance decreases drastically above $500{ }^{\circ} \mathrm{C}$. In Section 3, we reported results of the fast reactor program [22] where HT-9 has shown to have adequate thermal creep properties to $650{ }^{\circ} \mathrm{C}$. If the SSTAR cladding temperature is to be increased to $650{ }^{\circ} \mathrm{C}$, the creep strength of the ferritic/martensitic steel must be improved, see Fig. 14. Development of fuel pin cladding materials and structural materials having greater strength at high temperatures is indicated in [67]. 
HT9 and T91 F/M Ste els

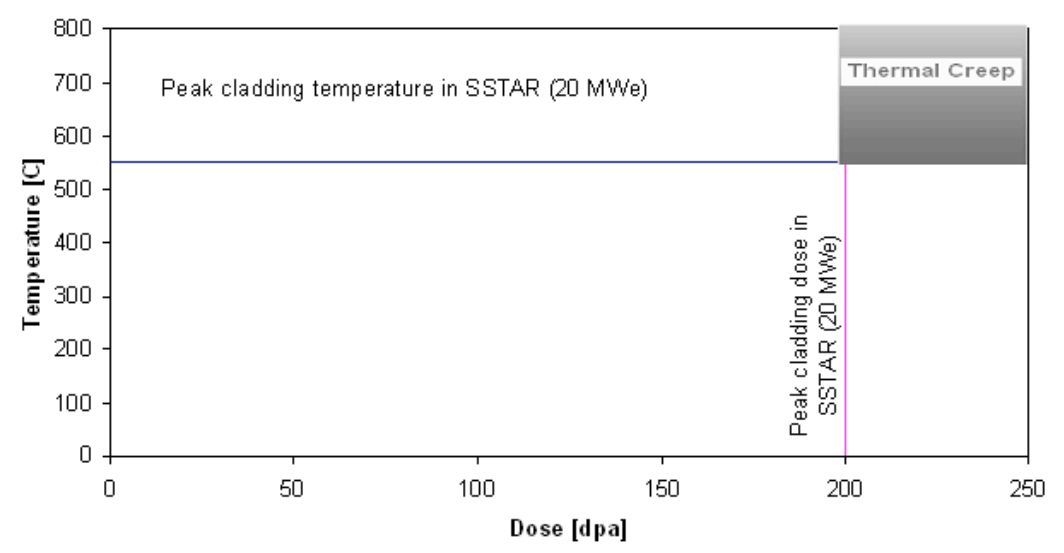

Fig. 14: Schematic diagram depicting the region where creep could be considered a problem in LFR.

Austenitic steels are used as reactor vessels and of out of core structural components in existing and planned fast breeder reactors and could be used in the LFR test reactor. Exposure to the fast neutrons radiation field (15-40 dpa) could be reduced by using preventive shielding of the vessel. The ferritic/martensitic option for the LFR vessel could be the modified 9Cr-1Mo alloy, 9Cr-1MoV (grade 91) alloy approved in ASME Code to $649{ }^{\circ} \mathrm{C}$ for high temperature structures, including pressure vessels. Ferritic steels of $9 \mathrm{Cr}-1 \mathrm{Mo}$ grade have been reported to show the lowest increase in DBTT among various ferritic-martensitic steels [8]. Embrittlement decreases as the operating temperature is increased. SSTAR vessel and internal operating temperatures are more favorable in this respect. The vessel and internals will have operating temperatures above $400^{\circ} \mathrm{C}$. This means the vessel will be subjected to temperatures above those currently used for commercial light-water reactor (LWR) vessel $\left(\sim 290^{\circ} \mathrm{C}\right)$. Embrittlement will be less of a concern for the higher temperature conditions because as temperature increases, irradiation effects decrease for the same irradiation exposure.

The exposure accumulated at the end-of-life will limit the LFR vessel integrity. Vessel exposures in the LFR test reactor have not been estimated yet, but they can be estimated to reach $\sim 60$ dpa after 40 years of life (EOL). In reactor pressure vessels of typical LWRs currently operating hardening and embrittlement are observed in A533B - A508Cl3 steels for exposures of $<1 \mathrm{dpa}$ at EOL. Here the discussion has to do with higher exposure values. However, the increase in DBTT (decrease in upper-shelf energy) saturates at high irradiation doses. The increase in DBTT (decrease in upper-shelf energy) has been shown to saturate in ferritic-martensitic steels at high irradiation doses [8]. It has been shown that embrittlement saturates with fluence in Sandvik HT9 (12Cr-1MoVW) steel irradiated up to 10 and 17 dpa at $365{ }^{\circ} \mathrm{C}$ in FFTF [68]. The magnitude of the shift in a Charpy impact test was found to be the same. 
Embrittlement is of considerable concern in ferritic-martensitic steels at irradiation temperatures less than $\sim 450{ }^{\circ} \mathrm{C}$ (see Fig. 15). In this respect, T-91 is a better candidate for the LFR vessel than HT-9; DBTT shift values have been found to be lower for T-91 than for HT-9 for the same exposure at the same irradiation temperature. It has been shown that shifts of $\sim 10^{\circ} \mathrm{C}\left(\sim 125^{\circ} \mathrm{C}\right)$ were obtained in ORNL 9Cr-2WVTa steel irradiated up to $10 \mathrm{dpa}$ at $365^{\circ} \mathrm{C}$ in FFTF while $\sim 125^{\circ} \mathrm{C}$ were obtained in Sandvik HT-9 [68]. Note that ORNL 9Cr$2 \mathrm{WVTa}$ can be considered as the reduced activation version of T-91 steel; Mo and $\mathrm{Nb}$ have been replaced by $\mathrm{W}$ and $\mathrm{Ta}$.

HT9 and T91 F/M Steels



Fig. 15: Schematic diagram depicting the region where embrittlement could be considered a problem in LFR.

The effects of radiation on fracture toughness of current operating reactor pressure vessels have received considerable attention. The vessel structure should withstand the service conditions safely and reliability throughout its predicted lifetime. Structural integrity assessments will require a materials database for ferritic-martensitic steels in the unirradiated and irradiated condition. Data for ferritic-martensitic steels in the irradiated condition is sparse or nonexistent. A materials testing program, conducted with irradiations performed under representative conditions, will help establish fracture toughness properties of low-alloy ferritic/martensitic steels. Recently, fracture toughness evaluation using the Master Curve has been accepted by ASTM and is a recommended standard since 2003 (ASTM E 1921-03 "Standard Test Method for Determination of Reference Temperature, $\mathrm{T}_{0}$, for Ferritic Steels in the Transition Range"). The benefit of the Master Curve procedure is that it gives a direct measure of the fracture toughness of the steel. This is of great value compared to Charpy tests. The ductile-to-brittle transition temperature obtained from Charpy tests depends on the initial un-irradiated condition. This is not the case for the Master Curve method. This recently developed methodology is already being implemented to describe the fracture behavior of reactor pressure vessels of existing LWRs. At present only few tests in the un-irradiated condition have been done for HT-9 and T-91 in the un-irradiated conditions [69]. Further experiments in the irradiated condition are needed if these materials are going to be used as structural components in the LFR test demonstrator. 


\section{Conclusions}

By selection of the reactor operating temperatures and neutron exposure, it is possible to construct a LBE or lead cooled reactor with an acceptable test life using existing materials such as HT-9, T-91 EP-823 and 316-L. The reactor would be an important research facility for use in developing advanced materials for the future SSTAR and its use in the GNEP. The combined neutron, temperature and coolant environment in such a facility would provide the unique testing needed to support advanced material development. Candidate materials for testing have been identified and analytical methods are being developed to guide material selection and processing to improve the materials for application at higher temperature.

Materials performance limits virtually all reactor technologies. Materials suitable for applications at higher temperatures, in corrosive environments, and in higher neutron irradiation fields are needed. However, if the good performance of the leading candidate materials identified is confirmed at temperatures below $550{ }^{\circ} \mathrm{C}$, and exposures below $\sim 100$ dpa, a demo lead or LBE cooled fast reactor project could be initiated in as little as 10 years. Thermal and corrosion control testing have been done at laboratory level. Under conventional operating conditions existing operating experience indicate that corrosion control is possible. Eliminating oxygen control has been envisaged. Alternates to oxygen control and alternate advanced corrosion resistant materials or surface treatments should be explored. This topic is the major focus of LFR R\&D.

LFR is widely considered as the next generation in fast reactor technology. To achieve maturity, $\mathrm{R} \& \mathrm{D}$ is needed to demonstrate the high-temperature applications of LFR. The lead or lead-bismuth high boiling point may allow operation at higher temperatures - however, this requires the development, testing and qualification of appropriate structural materials.

Higher burnups will require cladding materials with improved high-temperature strength and creep. Oxide-dispersed steels are the best candidate, but their irradiation properties, performance and compatibility with the fuel and the coolant have yet to be established.

Prediction of how these materials will perform under high exposures (radiation induced swelling, hardening and embrittlement) represents a challenge to the capabilities of present day available models. Multiscale modeling, i.e. modeling of materials at several interconnected length and time scales (together with experimental verification) is a powerful approach that can provide advanced materials solutions to this and other critical issues on materials for Gen-IV reactors.

The spectacular progress in the theoretical framework and the exceptional advances in parallel computing made in recent years are applied at LLNL to develop tools to calculate the structural and mechanical properties of alloys; in particular FeCr-based steels.

To characterize these materials and their behavior under the specified conditions, as well as to propose material-degradation mitigation alternatives, a very large volume of irradiation tests of material specimen matrices need to be performed. Under the present circumstances, where the number of irradiation test facilities is decreasing rapidly, such a program does not seem realistic. The re-emergence of interest and support for fast-spectrum reactor $R \& D$ 
renews the need for materials to sustain high fast neutron fluences, and opens future opportunity to apply advanced materials modeling to the problem. This modeling effort is a first step in the direction of further integrated-modeling approaches needed to guide the identification of Gen-IV future candidate materials. 


\section{References}

\section{[1] http://www.gnep.energy.gov/default.html}

[2] N. Brown, "Options for an Early LFR Technology Demonstrator: High-Confidence Design Options for Lead-Cooled Fast Reactors”, March 30, 2006

[3] J. J. Sienicki et al, "Interim Status Report on the Small Secure Transportable Autonomous Reactor (SSTAR)/Lead-Cooled Fast Reactor (LFR) and Related Research and Development", ANL-GenIV068, September 30, 2005.

[4] L. K. Mansur, A. F. Rowcliffe, R. K. Nanstad, S. J. Zinkle, W. R. Corwin, R. E. Stoller, "Materials needs for fusion, Generation IV fission reactors and spallation neutron sources - similarities and differences", Journal of Nucl. Mater. 329-333 (2004) 166-172.

[5] Y. Tateishi, S. Yuhara, I. Shibahara, M. Itoh, S. Nomura, Y. Sato, E. Yoshida, S. Shikakura, "Development of modified SUS 316 stainless steel as core material for fast breeder reactors", Journal of the Atomic Energy Society of Japan 30 (1988) 1005.

[6] French Rapsodie $1515 \mathrm{Ti}$

[7] W. J. Zinkle, P. J. Maziasz, R. E. Stoller, "Dose dependence of the microstructural evolution in neutronirradiated austenitic stainless steel”, Journal of Nucl. Mater. 206 (1993) 266-286

[8] Baldev Raj, S. L. Mannan, P. R. Vasudeva Rao, and M. D. Mathew, "Development of fuels and structural materials for fast breeder reactors", Sadhana 27, Part 5 (October 2002) 527-558.

[9] T. R. Allen, J. I. Cole, D. L. Trybus, D. L. Porter, H. Tsai, F. Garner, E. A. Kenik, t. Yoshitake, J. Ohta, "The effect of dose rate on the response of austenitic stainless steels to neutron irradiation", Journal of Nucl. Mater. 348 (2206) 148-164

[10] J. I. Cole, T. R. Allen, H. Kusanagi, K. Dohi, J. Ohta, "Microstructure and post-irradiation annealing behavior of 20\% cold-worked 316 stainless steel" Microstructural Processes in Irradiated Materials 2000. Symposium (Mater. Res. Soc. Proceedings Vol. 650). Mater. Res. Soc. 2001, pp. R2.9.1-6. Warrendale, PA, USA.

[11] E. Loewen, A. T. Tokuhiro, "Status of Research and Development of the Lead-Alloy-Cooled Fast reactor", Journal of Nucl. Sci. and Tech. 40 (2003) 614-627.

[12] Jinsuo Zhang, Ning Li, Yitung Chen, A.E. Rusanov, "Corrosion behaviors of US steels in flowing lead-bismuth eutectic (LBE)", Journal of Nucl. Mater. 336 (2005) 1-10

[13] N. Li, "Delta Testing of Surface Treated Materials", AFCI Program, LANL, Dec. 6, 2004 (private communication).

[14] T. Zaleski, M. Caro, W. Halsey, PVP2006-ICPVT11-93626: "Thermal effects on thin laser-peened ferritic-martensitic samples", presented at PVP2006-ICPVT11-93626 ASME Pressure Vessels \& Piping Division Conference, July23-27, 2006, Hyatt Regency Vancouver, Vancouver, BC, Canada (to be published in LLNL-UCRL report).

[15] N. Li, "Lead-Alloy Coolant Technology and Materials - Current State of Art”, ICAPP'05, May 15-19, 2005, TBA, Seoul, Korea. 
[16] T. R. Allen, L. Tan, J. D. Tucker, J. Gan, G. Gupta, G. S. Was, S. Shutthanandan, S. Thevuthasan, "Radiation Resistance of Advanced Ferritic-Martensitic Steel HCM12A", June 2004

www.wun.ac.uk/nuclearsci/research themes/materials/pdfs/ASTM22ndSymposium3.pdf

[17] D.S. Gelles, Microstructural development in reduced activation ferritic alloys irradiated to $200 \mathrm{dpa}$ at $420^{\circ} \mathrm{C}^{\prime}$, Journal of Nucl. Mater. 212-215 (1994) 714-719.

[18] D.S. Gelles, "Microstructural examination of commercial ferritic alloys at 200 dpa", Journal of Nucl. Mater. 233-237 (1996) 293.

[19] Klueh, Kai, Alexander, "Microstructure-mechanical properties correlation of irradiated, conventional and reduced-activation martensitic steels", Journal of Nucl. Mater. 225 (1995) 175-186

[20] F.A. Garner, M.B. Toloczko, B.H. Sencer, "Comparison of swelling and irradiation creep behavior of fcc-austenitic and bcc-ferritic/martensitic alloys at high neutron exposure", Journal of Nucl. Mater. 276 (2000) 123-142.

[21] R. L. Klueh, D. R. Harries, "High-chromium Ferritic and Martensitic Steels for Nuclear Applications", ASTM stock number: MONO3, (2001), American Society for Testing and Materials, West Conshohocken, PA.

[22] T. Allen, and R. L. Klueh, "Advanced accelerator applications, cladding and duct review”, Argonne National Laboratory Report, ANL-AAA-025, August 31, 2002.

[23] R. L. Klueh, N. Hashimoto, R. F. Buck, M. A. Sokolov, "A potential new ferritic/martensitic steel for fusion applications", Journal of Nucl. Mater. 283-287 (2000) 697-701.

[24] JNMZ

[25] S. Jitsukawa, M. Tamura, B. van der Schaaf, R. L. Klueh, A. Alamo, C. Petersen, M. Schirra, P. Spaetig, G. R. Odette, A. A. Tavassoli, K. Shiba, A. Kohyama, A. Kimura "Development of an extensive database of mechanical and physical properties for reduced-activation martensitic steel $\mathrm{F} 82 \mathrm{H}$, Journal of Nucl. Mater. 307-311 (2002) 1798-186

[26] Ho Jin Ryu, A. M. Yacout, Y. S. Kim, G. L. Hofman, "Thermal creep correlations of HT-9 ferritic steel for advanced fast reactors", Nuclear Fuels and Structural Materials for the Next Generation Nuclear Reactors, Embedded Topical Meeting, 2006 ANS Annual Meeting June 4-8, 2006, Reno Nevada, US.

[27] J. L. Seran, A. Alamo, A. Maillard, H. Touron, J. C. Brachet, P. Dubuisson, O. Rabouille, "Pre- and post-irradiation mechanical properties of ferritic-martensitic steels for fusion applications: EM10 base metal and EM10/EM10 welds", Journal of Nucl. Mater. 212-215 (1994) 588-593.

[28] E. Lucon and A. Almazouzi, "Irradiation behaviour of three candidate structural materials for ADS systems: EM10, T-91, and HT-9 (F/M Steels)",SCK•CEN, Mol, Belgium, EUROMAT 2005 -Prague, Czech Republic, Sep 5-8, 2005

[29] R.L. Klueh, Ji-Jung Kai, D.J. Alexander, "Microstructure-mechanical properties correlation of irradiated conventional and reduced-activation martensitic steels", Journal of Nucl. Mater. 225 (1995) 175-186.

[30] N. Li, "Candidate Materials and Coolant Candidate Materials and Coolant Technology for Lead Technology for Lead-Alloy Cooled Alloy Cooled Nuclear Systems Nuclear Systems: Metallic Alloys, Ceramics and Metallic Alloys, Ceramics and Composites Composites", COE-INES-1, Tokyo, Japan Nov. 2004. 
[31] N. Li; "Active control of oxygen in molten Lead-Bismuth Eutectic systems to prevent steel corrosion and coolant contamination"; Journal of Nucl. Mater. 300 (2002) 73-81.

[32] N. Li, "Gen IV LFR Work Package L0502J01 (LFR Materials -LANL) Milestone Report: DELTA Loop Experiments, Operations and Corrosion: Appendix III, Summary of Corrosion Test Results", October 2004.

[33] K. Ehrlich, J. Konys, L. Heikinheimo, "Materials for high performance light water reactors", JNM 327 (2004) 140-147.

[34] Koji Hata, Kazuyuki Hara, Minoru Takahashi, "Experimental Studies on Steel Corrosion in LeadBismuth with Steam Injection", http://www.nr.titech.ac.jp/coe21/eng/events/ines1/pdf/101_hata.pdf

[35] LFR-SC Plan Outline.doc (C. Smith, private communication, 2006).

[36] W. Corwin, L. Snead, S. Zinkle, R. Nanstad, A. Rowcliffe, L. Mansur, R. Swindeman, W. Ren, D. Wilson, T. McGreevy, P. Rittenhouse, J. Klett, T. Allen, J. Gan, K. Weaver, "The Gas Fast Reactor (GFR) Survey of Materials Experience and R\&D Needs to Assess Viability", ORNL/TM-2004/99, April 30, 2004.

[37] J. Zhang, N. Li, Y. Chen, A. E. Rusanov, "Corrosion behaviors of US steels in flowing lead-bismuth eutectic (LBE)”, JNM 336 (2005) 1-10.

[38] S.I. Porollo, A.M. Dvoriashin, Yu.V. Konobeev, F.A. Garner, "Microstructure and mechanical properties of ferritic/martensitic steel EP-823 after neutron irradiation to high doses in BOR-60", JNM 329-333 (2004) 314.

[39] S .I. Porollo, Yu. V. Konobeev, and A. M. Dvoriashin, N. I. Budylkin, E. G. Mironova, M. V. Leontyeva-Smirnova, and A. G. Loltukhovsky and F. A. Garner, "Irradiation creep and mechanical properties of two ferritic martensitic steels irradiated in the BN-350 fast reactor", http://aaa.lanl.gov/documents/pdf/AFC-03-307-PNNL.pdf

[40] N. Brown, M. Caro, W. G. Halsey, M. B. Toloczko, F. A. Garner, "Post-Irradiation Examination Program for FFTF and CIS Irradiated F/M Materials", UCRL-TR-216098, March 2005.

[41] A.V. Vatulin, B.D. Rogozkin, N.M. Stepennova, Yu.E. Fedorov, O.A. Ustinov, P.P. Poluektov, L.P. Suhanov, A.G. Sila-Novitsky, "Mononitride Uranium-Plutonium Fuel of Fast Lead-cooled Reactors", 11th International Conference on Nuclear Engineering, Tokyo, Japan, April 20-23, 2003 ICONE1136414 .

[42] S. Jitsukawa et al. Journal of Nucl. Mater. 307-311 (2002)

[43] A. Kohyama, Y. Kohno, M. Kuroda, A. Kimura, F. Wan, Journal of Nucl. Mater. 258-263 (1998) 1319

[44] J. Rensman et al., Journal of Nucl. Mater. 307-311 (2002)

[45] S. J. Zinkle et al Journal of Nucl. Mater. 307-311 (2002) 31-42

[46] S. Ukai, T. Narita, A. Alamo b, P. Parmentier, "Tube manufacturing trials by different routes in 9CrWODS martensitic steels", Journal of Nucl. Mater. 329-333 (2004) 356-361.

[47] D.T. Hoelzer, G.R. Odette, M.J. Alinger, D.S. Gelles, A.F. Rowcliffe, R.L Klueh, B.A. Pint, P.J. Maziasz, "Advanced Alloy Systems", Fusion Materials Science Peer Review, August 27-28, 2001, University of California-Santa Barbara UCSB. 
[48] M.B. Toloczko, D.S. Gelles, F.A. Garner, R.J. Kurtz, K. Abe, "Irradiation creep and swelling from 400 to $600{ }^{\circ} \mathrm{C}$ of the oxide dispersion strengthened ferritic alloy MA957", Journal of Nucl. Mater. 329-333 (2004) 352-355.

[49] S. Yamashita, N. Akasaka, S. Ohnuki, "Nano-oxide particle stability of 9-12Cr grain morphology modified ODS steels under neutron irradiation", Journal of Nucl. Mater. 329-333 (2004) 377-381.

[50] I.-S.Kim, J. D. Hunn, N. Hashimoto, D. L. Larson, P.J. Maziasz, K. Miyahara, E. H. Lee, "Defect and void evolution in oxide dispersion strengthened ferritic steels under $3.2 \mathrm{MeV} \mathrm{Fe}+$ ion irradiation with simultaneous helium injection", Journal of Nucl. Mater. 280 (2000) 264-274.

[51] H. Sakasegawa, S. Ohtsuka, S. Ukai, H. Tanigawa, M. Fujiwara, H. Ogiwara, A. Kohyama, "Microstructural evolution during creep of 9Cr-ODS steels", Fusion Engineering and Design, vol.81, no.8-14, Feb. 2006, pp. 1013-18.

[52] G. Benamati, P. Buttol, V. Imbeni, C. Martini and G. Palombarini; "Behavior of materials for accelerator driven systems in stagnant molten lead"; Journal of Nucl. Mater. 279 (2000) 308-316.

[53] V. Rohr, A. Donchev, M. Schutze, A. Milewska, FJ Perez, "Diffusion coatings for high temperature corrosion protection of 9-12\%Cr steels", Corrosion Engineering, Science and Technology, vol.40, $\mathrm{N}^{\mathrm{o}} 3$, Sept. 2005, pp. 226-32.

[54] M.H. Mathon, Y. de Carlan, G. Geoffroy, X. Averty, A. Alamo, C.H. de Novion, "A SANS investigation of the irradiation-enhanced a-a' phases separation in 7-12 Cr martensitic steels", Journal of Nucl. Mater. 312 (2003) 236-248.

[55] M. Caro, W. G. Halsey, J. Marian, E. Martinez, J. Knap, V. Bulatov, M. Victoria, "Critical Issues on Materials for Gen-IV Reactors", poster presentation American Nuclear Society ANS Annual Meeting in Reno, Nevada (June 4-8, 2006).

[56] M. Caro, P. Klaver, H. Dogo, R. Till, A. Caro, " Point defects and precipitation in Fe-Cr alloys", proposed abstract for the Symposium JJ on Structural and Refractory Materials for Fusion and Fission Technologies, Materials Research Society MRS Fall Meeting, November 27 -Dec 1, 2006.

[57] A. Caro, M. Caro, E. M. Lopasso, and D.A. Crowson, "Influence of ab initio energetics on the thermodynamics of Fe-Cr alloys", (Jul 2006, to be published in APL).

[58] A. Caro, D. A. Crowson, M. Caro, "Classical many-body potential for concentrated alloys and the inversion of order in iron-chromium alloys", Phys. Rev. Letters 95 (2005) 0757021-4

[59] A. Caro, P. Turchi, M. Caro and E. M. Lopasso, "Analysis of capabilities and limitations of EAM potentials to describe alloy thermodynamics”, Journal of Nucl. Mater. 336 (2005) 233-242.

[60] P. Olsson, I. A. Abrikosov, L. Vitos, J. Wallenius, "Ab initio formation energies of Fe-Cr alloys", Journal of Nucl. Mater. 321 (2003) 84-90

[61] T. Diaz de la Rubia and M. W. Guinan, Phys. Rev. Letters 66 (1991) 2766.

[62] A. J. E. Foreman, W. J. Phytian, C. A. English, Phil. Mag. A 66 (1992) 671.

[63] A. F. Calder, and D. J. Bacon, Journal of Nucl. Mater. 207 (1993) 25.

[64] D. Terentyev, L. Malerba, and A. V. Barashev, "On the correlation between self-interstitial cluster diffusivity and irradiation-induced swelling in Fe-Cr alloys”, Phil. Mag. Letters 85 (2005) 587.

[65] E. A. Little, D. A. Stow, Journal of Nucl. Mater. 87 (1979) 25 
[66] F. A. Garner, M. B. Toloczko, B. H. Sencer, J. Nucl. Mater 276 (2000) 123.

[67] J. J. Sienicki, A. V. Moisseytsev, P. A. Pfeiffer, W. S. Yang, M. A. Smith, S. J. Kim, Y. D. Bodnar, D. C. Wade, and L. L. Leibowitz, "SSTAR Lead-cooled, Small Modular Fast Reactor with Nitride Fuel", Workshop on Advanced Reactors with Innovative Fuels, ARWIF-2005, Oak Ridge, February 16-18, 2005

[68] ORNL/TM-2004/176

[69] R. Nanstad, M. A. Sokolov, "Fracture Toughness Vis-aVis the Master Curve for Some Advanced Reactor Pressure Vessel and Structural Steels", EUROMAT 2005, Prague, Czech Republic, 5-8 September 2005. 